\title{
Commercially Available Smartphone Apps to Support Postoperative Pain Self-Management: Scoping Review
}

Chitra Lalloo $^{1}$, PhD; Ushma Shah ${ }^{2}$, DNB, EDRA, EDAIC, FRCA; Kathryn A Birnie ${ }^{1,3}$, PhD; Cleo Davies-Chalmers ${ }^{1}$; Jordan Rivera $^{1}$, BScN; Jennifer Stinson ${ }^{1,3,4}, \mathrm{RN}, \mathrm{PhD}$, CPNP; Fiona Campbell ${ }^{4,5}$, MD, FRCA

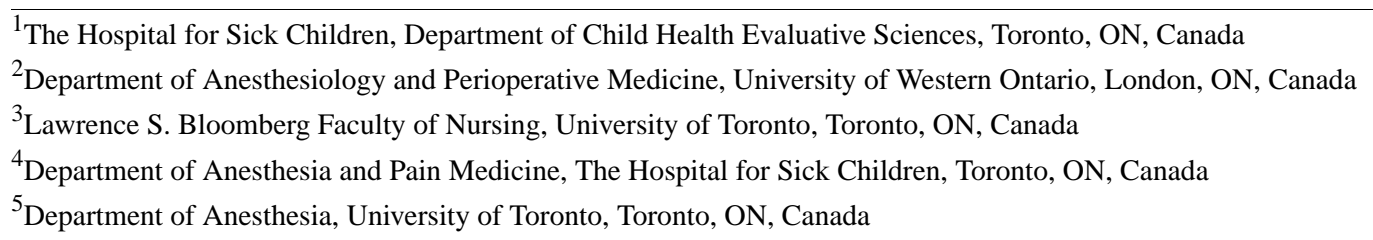

Corresponding Author:

Chitra Lalloo, $\mathrm{PhD}$

The Hospital for Sick Children

Department of Child Health Evaluative Sciences

686 Bay Street

Toronto, ON, M5G1X8

Canada

Phone: 14168137654 ext 302332

Fax: 14168138501

Email: chitra.lalloo@sickkids.ca

\section{Abstract}

Background: Recently, the use of smartphones to deliver health-related content has experienced rapid growth, with more than 165,000 mobile health (mHealth) apps currently available in the digital marketplace. With 3 out of 4 Canadians currently owning a smartphone, mHealth apps offer opportunities to deliver accessible health-related knowledge and support. Many individuals experience pain after surgery, which can negatively impact their health-related quality of life, including sleep, emotional, and social functioning. Smartphone apps that provide remote real-time monitoring and symptom management have the potential to improve self-management skills in patients experiencing postoperative pain. Increased confidence and practice of self-management skills could contribute to decreased postoperative pain and reduce risk of developing persistent pain. Published reviews of general pain self-management apps demonstrate a lack of evidence-based content, theoretical grounding, and health care professional involvement. However, no review to date has focused on the app marketplace specific for individuals with postoperative pain.

Objective: The aim of this study was to characterize and critically appraise the content and functionality of commercially available postoperative pain self-management apps.

Methods: An electronic search and extraction was conducted between December 2016 and March 2017 of the official Canadian app stores for the three major smartphone operating systems (iPhone operating system [iOS], Android, and Windows). Stores were searched separately using predetermined search terms. Two authors screened apps based on information provided in the public app description. Metadata from all included apps were abstracted into a standard spreadsheet. Two authors verified the data with reference to the apps and downloaded apps themselves. The content and functionality of each app as it pertained to postoperative pain self-management was rated.

Results: A total of 10 apps met the inclusion criteria. All included apps were designed exclusively for the Android platform. Education was the most common self-management feature offered $(8 / 10,80 \%)$, with none of the apps offering features related to goal setting or social support. Overall, no single app was comprehensive in terms of pain self-management content. Five (50\%) apps reported the involvement of a health care provider in their development. However, not a single app involved end users in their development, and none of the apps underwent scientific evaluation. Additionally, none of the apps were designed for use in pediatric patients.

Conclusions: Currently available postoperative pain apps for patients lack evidence-based content, goal setting, and social support functions. There is a need to develop and test comprehensive theory-based apps to support patients with pain self-management care following surgery. 
(JMIR Mhealth Uhealth 2017;5(10):e162) doi: 10.2196/mhealth.8230

\section{KEYWORDS}

pain, postoperative; smartphone; mobile applications; review; pain management; self care

\section{Introduction}

\section{Background}

More than $80 \%$ of patients experience acute postoperative pain after surgery, of whom approximately $75 \%$ report their pain intensity as moderate, severe, or extreme [1,2]. Unrelieved or undertreated acute postoperative pain can delay remobilization, lead to increased opioid use and related side effects, and negatively impact all aspects of health-related quality of life [3-5]. Greater confidence in one's ability to control pain is referred to as pain coping self-efficacy. Improvements in pain coping self-efficacy may contribute to decreased postoperative pain and reduced risk for developing persistent postoperative pain, an expensive and debilitating health problem [6,7]. Thus, the prevention or minimization of postoperative pain is critically important.

Remote real-time monitoring and symptom management support for postoperative pain patients is a relatively new notion made possible by technological advances. Smartphones, for instance, are now widely used across the life span [8,9]. Smartphones have the potential to empower people with postoperative pain who are at increased risk for undertreatment of pain and disruption in activities of daily living [10]. Smartphones can support self-management by (1) improving self-monitoring of pain and other symptoms in everyday environments (eg, home, hospital settings), (2) promoting pain self-efficacy and appropriate self-care (eg, adherence to prescribed medications, cognitive-behavioral pain coping strategies), and (3) minimize barriers to optimal pain treatment (eg, lack of transportation to tertiary care centers) $[11,12]$.

\section{Existing Reviews of Pain Management Apps}

There are a growing number of generalized pain self-management smartphone apps available for users to download on their personal mobile devices. In a 2011 scoping review, Rosser and Eccleston identified 111 such apps [13]. A majority were designed for the iPhone (iPhone operating system, iOS) platform, with fewer being available for Android or BlackBerry operating systems. The primary app functions included education skills training (50.5\%; 56/111), self-monitoring (eg, pain diary, 26.1\%; 29/111), and relaxation training $(21.6 \%$; 24/111). Importantly, $85.6 \%$ (95/111) of the identified apps did not report the involvement of health care professionals in their design or evaluation of content. None of the apps were focused on postoperative pain [13]. In 2012, Reynoldson and colleagues conducted an updated search of the iOS and Android stores [14]. This search only included apps with a primary self-monitoring function (ie, allowing patients to track their pain episodes). Apps were excluded if their intended use was limited to pain from specific conditions such as arthritis, inflammatory bowel disease, or migraine. The authors identified 12 eligible apps, which then underwent content analysis and usability testing. Their review identified a lack of user and clinician engagement in pain app development, as well as variation in app quality [14]. In 2015, Lalloo and colleagues conducted an updated scoping review of available pain management apps [15]. A total of 279 apps met the inclusion criteria. Pain self-care skill support was the most common self-management function $(77.4 \% ; 216 / 279)$. Apps also purported providing patients with the ability to engage in pain education $(45.9 \%$; $128 / 279)$, self-monitoring $(19.0 \%$; $53 / 279)$, social support $(3.6 \% ; 10 / 279)$, and goal setting $(0.7 \%$; $2 / 279$ ). No apps were comprehensive in terms of pain self-management, with the majority of apps including only a single self-management function (58.8\%; 164/279). Additionally, only $8.2 \%$ (23/279) of the apps included a health care professional in their development, not a single app provided a theoretical rationale, and only 1 app underwent scientific evaluation [15].

\section{Objectives}

To our knowledge, no scoping review to date has focused on apps for postoperative pain management. In addition, no scoping reviews to date have sought to identify apps for both pediatric and adult users. Therefore, the objectives of this study were to (1) characterize the current field of patient-focused pain self-management apps across all major smartphone platforms in Canada; (2) critically appraise the content and functionality of these apps, including self-care skill support, pain education, self-monitoring, social support, and goal setting; and (3) identify gaps in the field to guide future development of an app to support individuals with postoperative pain.

\section{Methods}

An electronic search and extraction was conducted between December 2016 and March 2017 of the official Canadian app stores for the 3 major smartphone operating systems: iOS (iTunes App Store), Android (Google Play Store), and Windows (Windows Store). The entire stores were searched separately using predetermined search terms (ie, no restrictions related to store subcategories such as "health and wellness" were imposed). The search terms were as follows: "Pain, Surgery," "Pain, Post-Surgery," "Pain, Post-Surgical," "Pain, Operative," "Pain, Operation," "Pain Management, Surgery," "Pain Management, Post-Surgery," "Pain Management, Post-Surgical," "Pain Management, Operative," "Pain Management, Operation."

No limits were imposed related to language or date of app publication. Given that the process for app indexing exhibited variability across app stores, a calibration exercise was conducted before app selection in order to verify our ability to detect postsurgical pain apps. Specifically, we tested our search criteria for the ability to find postsurgical pain apps that were known to be currently available in the app stores. In all cases, our search criteria identified the apps we expected to find. 


\section{Screening and Selection of Apps}

Apps were included in the study if the primary intended user of the app was a person undergoing surgery, and a stated goal of the app was to provide education, tools, or advice related to managing pain after surgery. Apps were excluded if they focused only on the services offered by specific hospitals because they were intended as advertisements for these sites. These clinic apps typically included only lists of the pain management services and personnel available at the hospital and directions to the clinic rather than self-management programming. Apps were also excluded if they were classified as $e$-books by the respective app store or were judged by the reviewers as such. An $e$-book was defined as an app that did not provide any additional content or functionality beyond a textbook (eg, written content identical to a book). Authors performed app selection independently and all discrepancies regarding selection were resolved through discussion with a third author. Apps were screened based on the information provided in the app description section of each respective app store. Apps that met all screening criteria were downloaded and reviewed to confirm eligibility, and then data abstraction and content assessment were completed.

\section{Data Abstraction}

Metadata from all included apps were abstracted into a Microsoft Excel spreadsheet. Abstracted metadata included app name, URL, app description, customer rating on the day of store search, number of installations, and price. A systematic approach to data abstraction was used. Specifically, 2 authors (CDC and JR) abstracted all data and 2 others (CL and US) verified the data with reference to the app website and the downloaded apps themselves.

\section{Content Assessment}

To assess the comprehensiveness of app self-management content, the following criteria were used: (1) having a postoperative pain tracking function, (2) ability to set goals related to improving pain and functioning, (3) provision of skills training related to specific pain self-care strategies, (4) provision of social support, (5) provision of education related to surgery, and (6) provision of education related to pain after surgery. For each criterion, we assessed coverage as either present or absent. Similar criteria were used in our 2015 published scoping review [15] of general pain self-management apps. This list is based on the features of pain self-management programs that have been examined for effectiveness in scientific trials [16-19].

We also assessed whether a regulated health care professional had provided clinical expertise related to development of the app content and function. An app was required to reference the involvement of a health care professional listed in the Ontario Regulated Health Professions Act [20] to meet this criterion.
This list contains 26 health care regulatory colleges to whom the Ontario government has endowed the capacity to regulate the practices of corresponding health care professionals to ensure safe and ethical patient care. The list includes professions such as physicians, nurses, and physiotherapists. If an app claimed the input of a profession that was not listed in the Act in its development, we assessed the health care professional involvement as absent. The involvement of end users (eg, surgery patients) in app development was also documented as present or absent. Apps were reviewed to determine whether they were designed for pediatric (aged 18 years or younger) or adult users.

The app store descriptions were also screened for any reference to the app being part of formal scientific research. The app description and corresponding developer website (if available) were reviewed to determine whether any specific theoretical framework had been used to guide the development of app content. Finally, large publicly accessible scientific literature databases (ie, NCBI PubMed and Google Scholar) were searched using the app name as a query for any published research related to the app. The MyHealthApps website was also reviewed as per the methods of de la Vega and Miro [21]. Descriptive statistics were used to summarize the results of the content assessment.

\section{Results}

\section{App Screening}

Our search strategy across iTunes, Windows, and Google Play app stores identified a total of 1019 apps (923 Android, 93 iPhone, and 3 Windows), which were screened according to the inclusion and exclusion criteria. Only 10/1019 apps (0.98\% of total screened) met all inclusion criteria and were included in the analysis (see Figure 1 for PRISMA [Preferred Reporting Items for Systematic Reviews and Meta-Analyses] flowchart) [22]. All included apps were designed exclusively for the Android platform (see Table 1 for included apps).

\section{Self-Management Content of Reviewed Apps}

Education related to postoperative pain was the most common self-management feature offered across the identified apps. This educational content largely focused on self-care advice following surgery, particularly physiotherapy exercises to support return to mobility. However, there was no specific content related to emotional factors such as anxiety or catastrophizing related to surgery. As well, none of the apps offered features related to goal setting or social support. Overall, no single app was comprehensive in terms of pain self-management content. Additionally, no apps were designed specifically for pediatric patients. See Figure 2 for a summary of the self-management components across all reviewed apps. 
Table 1. Postoperative pain apps included in the review.

\begin{tabular}{lll}
\hline$\#$ & App & Developer \\
\hline 1 & Activity Heals 1on1 & Elevenity \\
2 & Breast Implant Exercises & Chicago Plastic Surgery \\
3 & BW MyTENS & Visiomed Lab \\
4 & Doado Your Health Companion & Alex Spriet \\
5 & Fuse-Post Op. Journal & Imbas Solutions \\
6 & Healing Power & Phil Shapiro \\
7 & My Hip Rehab & App Squid \\
8 & Physiotherapy Help Guide & Creativity Knowledge App \\
9 & Pocket Physio & Care UK HC \\
10 & Surgeon on Call & Phoenix Medical Consulting \\
\hline
\end{tabular}


Figure 1. PRISMA (Preferred Reporting Items for Systematic Reviews and Meta-Analyses) flowchart of app review process.

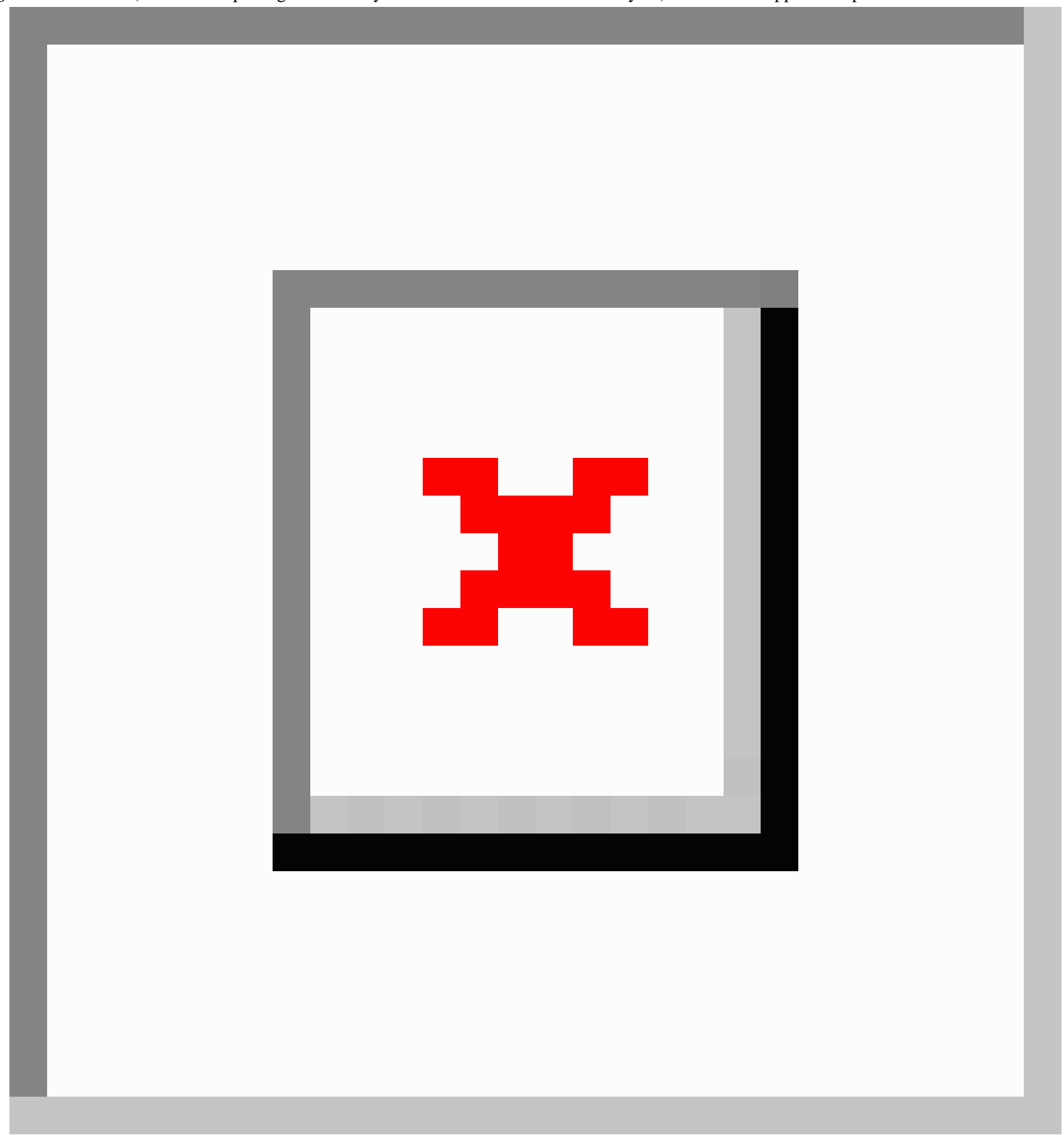


Figure 2. Self-management content across reviewed apps.

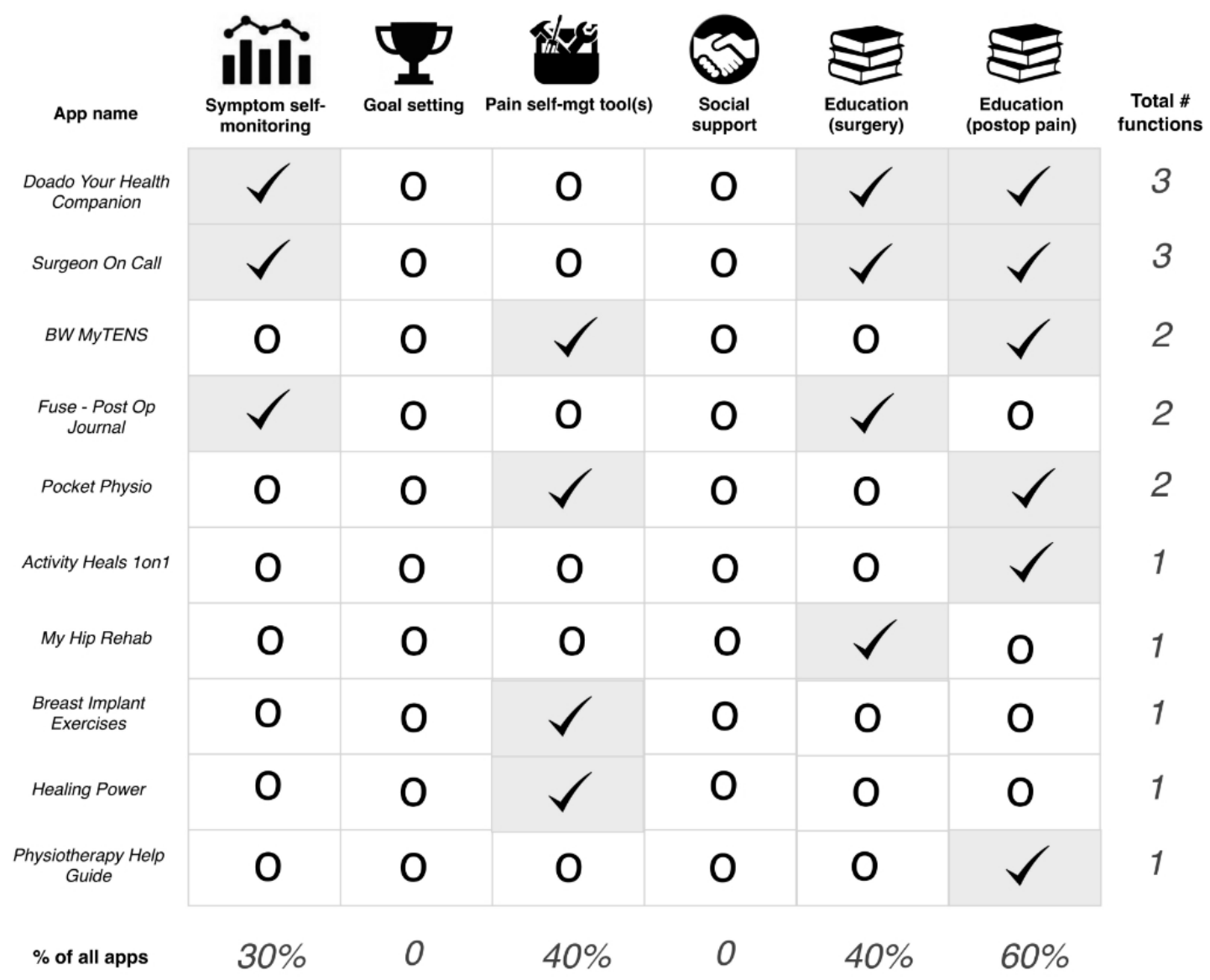

\section{App Cost, Customer Ratings, and Number of Installs}

Most apps $(8 / 10,80 \%)$ were free to download with the exceptions of Surgeon on Call and My Hip Rehab, which were associated with charges of Can $\$ 0.99$ and Can $\$ 10.22$, respectively. App store customers had the option of rating each app on a scale ranging from 1 to 5 stars (no anchors provided).
There was a high variability in the number of users who chose to rate each app (range of 2-380 raters per app). As seen in Figure 3, the average customer rating ranged from 2 to 4.8 stars. However, fewer than 10 customers reviewed most $(7 / 10,70 \%)$ of the apps. The number of app installs ranged from as low as 10 to as high as 100,000 across apps (see Table 2).

Table 2. App installations. Categories provided by Android Google Play Store. Data collected on April 26, 2017.

\begin{tabular}{ll}
\hline Number of installs & Apps \\
\hline $10-50$ & Surgeon on Call; My Hip Rehab \\
$100-500$ & Fuse-Post Op. Journal; Healing Power \\
$500-1000$ & Activity Heals 1on1; BW MyTENS \\
$1000-5000$ & Breast Implant Exercises \\
$5000-10000$ & Pocket Physio \\
$10,000-50,000$ & Doado Your Health Companion \\
$50,000-100,000$ & Physiotherapy Help Guide \\
\hline
\end{tabular}


Figure 3. Customer-generated app ratings. *No customer ratings, or less than 2 ratings, were available for three apps: Fuse - Post-Op Journal, Surgeon on Call, and Healing Power.

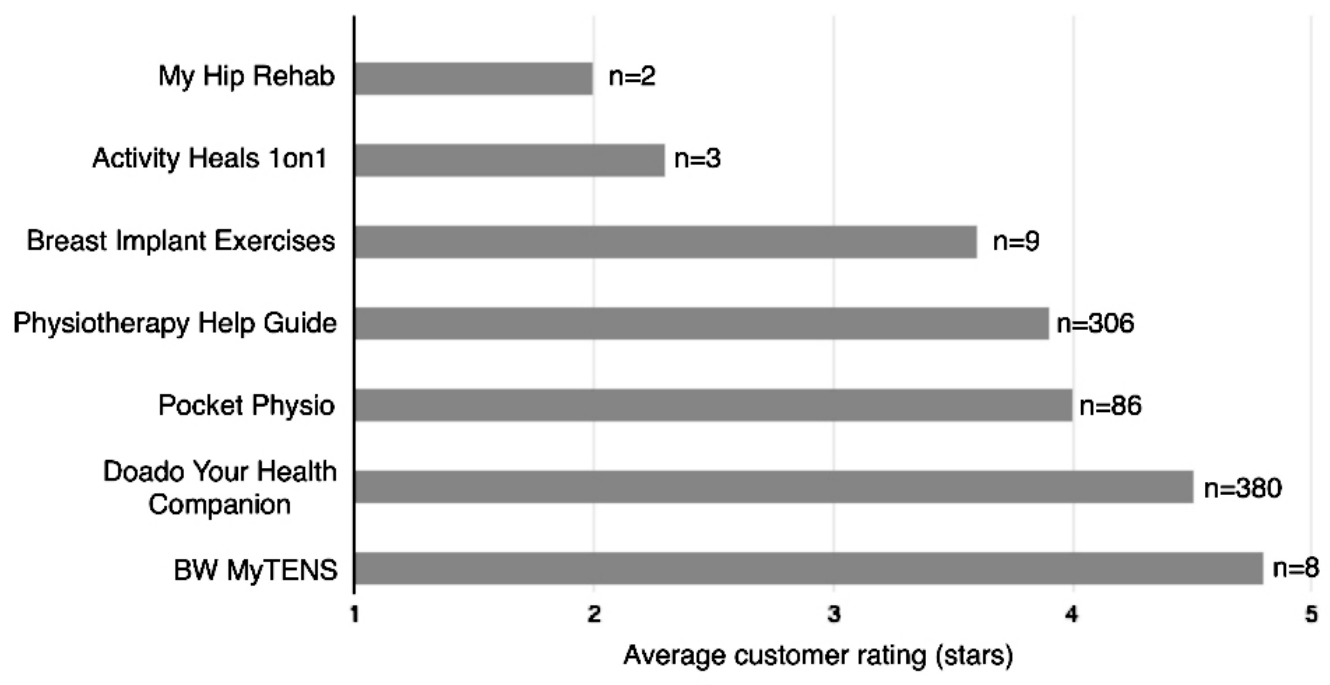

\section{Involvement of Health Care Providers, End Users, and Scientific Evaluation}

Overall, 5/10 (50\%) apps reported the involvement of a health care provider in their development. In summary, Doado Your Health Companion and Pocket Physio involved a physiotherapist, while Breast Implant Exercises and Healing Power involved a physician, and Surgeon on Call involved a specialist (surgeon). The other apps did not report any involvement of health care professionals in their development. None of the apps reported involvement of end users (eg, surgical patients) in their development. No evidence was found indicating that any of the apps had been scientifically evaluated.

\section{Discussion}

\section{Principal Findings}

This review demonstrates the paucity of high-quality apps that are commercially available to support self-management of postoperative pain for either adult or pediatric users. All included apps were designed exclusively for the Android platform. Education was the most common self-management feature offered $(8 / 10,80 \%)$, while none of the apps offered features related to goal setting or social support. Overall, no single app was comprehensive in terms of pain self-management content. Five $(5 / 10,50 \%)$ apps reported the involvement of a health care provider in their development. However, not a single app involved end users in their development and none of the apps underwent scientific evaluation. Additionally, none of the apps were designed for use in pediatric patients.

Customer ratings for the apps were moderate on average (mean 3.6, standard deviation 1.1). However, it is important to highlight that very few users chose to provide an app rating. For instance, while Pocket Physio reported between 5000 and 10,000 installs, only 86 users provided a rating (0.86-1.7\%). No ratings, or less than the required minimum of 2 ratings, were provided for $30 \%$ (3/10) of the apps. All of the identified apps were designed exclusively for Android devices with no interoperability for iOS and Windows devices. This finding is in contrast to the
2015 systematic review of generic pain apps, where the majority of identified apps were designed for the iOS platform [15].

The adequacy of existing apps can be assessed relative to recently published clinical practice guidelines for evidence-based management of postoperative pain across the life span [23]. Relevant recommendations include the delivery of individually tailored preoperative education and perioperative pain management planning, the use of validated pain assessment tools to track response to pain interventions and inform treatment adjustments as needed, as well as the use of evidence-based, nonpharmacological pain management (eg, cognitive behavioral strategies, physical modalities) in conjunction with indicated pharmacological modalities [23]. Compared against these guidelines, none of the reviewed apps uniquely fulfill all recommended criteria of education (surgery and pain), symptom self-management, and pain self-management strategies. Furthermore, none of the apps offer the ability to prespecify a postoperative pain management plan or to consider the relevance of managing presurgical pain to postsurgical outcomes.

A complex myriad of surgical, psychological, socioenvironmental, and patient-related risk factors have been shown to influence postsurgical pain experience [24]. Pre- and postsurgical psychological factors associated with increased pain include anxiety, depression, low self-efficacy, and the tendency to catastrophize about pain [24-26]. Recent reviews and meta-analyses identify psychological treatments delivered preoperatively, postoperatively, or both, to effectively reduce postoperative pain [23,27]. Many of these strategies, such as distraction, relaxation, and guided imagery techniques, can be easily delivered via mHealth platforms. The ability of self-management apps to target psychosocial risk factors is plausible, given existing evidence supporting the use of smartphones to effectively deliver interventions to reduce symptoms of anxiety and depression [28], particularly when strategies are available in the moment when people are engaged in their everyday lives [29].

Despite the focus of many apps on physical strategies in recovery from surgery, none included goal setting. Goal setting 
is a critical function in smartphone apps targeting increased physical activity [30]. In addition to increasing risk for postsurgical pain, depression, anxiety, and low self-efficacy are also identified as barriers to adherence to physiotherapy treatment [31]. Apps that are designed to pair psychological and physical pain self-management strategies with goal setting may be particularly effective for reducing pain and enhancing postsurgical outcomes.

Concurring with the findings of earlier app reviews [13,15,32], this study demonstrates that existing postoperative pain apps lack empirical evidence of evaluation. This finding continues to raise concerns about the trustworthiness and effectiveness of commercially available apps for helping individuals to manage their postoperative pain. In contrast to previous reviews, $50 \%$ $(5 / 10)$ of the identified postoperative pain apps reported inclusion of a health care provider in their development. While this is a positive development, it would be informative for app developers to more explicitly describe the nature of provider input.

Moreover, none of the apps explicitly involved end users (people with postoperative pain) in their development. It has been recommended that patient-focused apps be developed as per a user-centered design (UCD) approach [33]. UCD is "characterized by a focus on the user, and on incorporating the user's perspective in all stages of the design process" [34]. Application of UCD has been associated with improved user acceptance, satisfaction, and engagement [35]. Given the limitations of existing apps, it is important that future app development to support postoperative pain management adopt the UCD principles.

\section{Limitations}

Given that the Web-based app searches were conducted within Canada, the results reflect the Canadian app marketplace. Due to the geographic search restrictions of the online app stores, this limitation also applies to other published app reviews (eg, Rosser and Eccleston [13] and Reynoldson et al [14] focused on the United Kingdom; Lalloo et al [15] focused on Canada). Thus, there may be differences in the commercially available postoperative pain apps in other countries. Additionally, while the Google Play Store (which contained all included apps) allows users to rate their app experience, their 1 to 5 scale does not have defined anchors. This lack of definition limits our ability to interpret the factors that are driving customer ratings. Furthermore, since app customers are not required to provide ratings, there is a high frequency of missing rating data in comparison with the reported number of installs.

\section{Conclusions}

Currently available postoperative pain apps are characterized by a lack of evidence-based content, goal setting, and social support functions and are not targeted to pediatric users. There is a need to develop and evaluate comprehensive, theory-based apps to better support patients with pain self-management care following surgery.

\section{Conflicts of Interest}

Authors CL, KAB, JNS, and FC conduct mHealth research and are involved in the development of pain self-management apps. These apps are described at the websites of PainQuILT (an evidence-based pain assessment and tracking tool for people with chronic pain) and the Improving Outcomes in Child Health through Technology (iOUCH) lab, a part of the Child Health Evaluative Sciences (CHES) research program at The Hospital for Sick Children in Toronto, Ontario.

\section{References}

1. Apfelbaum JL, Chen C, Mehta SS, Gan TJ. Postoperative pain experience: results from a national survey suggest postoperative pain continues to be undermanaged. Anesth Analg 2003 Aug;97(2):534-540. [Medline: 12873949]

2. Gan TJ, Habib AS, Miller TE, White W, Apfelbaum JL. Incidence, patient satisfaction, and perceptions of post-surgical pain: results from a US national survey. Curr Med Res Opin 2014 Jan;30(1):149-160. [doi: 10.1185/03007995.2013.860019] [Medline: 24237004]

3. Taylor RS, Ullrich K, Regan S, Broussard C, Schwenkglenks M, Taylor RJ, PAIN-OUT investigators. The impact of early postoperative pain on health-related quality of life. Pain Pract 2013 Sep;13(7):515-523. [doi: 10.1111/papr.12026] [Medline: 23279591]

4. MacLaren Chorney J, Twycross A, Mifflin K, Archibald K. Can we improve parents' management of their children's postoperative pain at home? Pain Res Manag 2014;19(4):e115-e123 [FREE Full text] [Medline: 25106030]

5. Pagé MG, Stinson J, Campbell F, Isaac L, Katz J. Identification of pain-related psychological risk factors for the development and maintenance of pediatric chronic postsurgical pain. J Pain Res 2013;6:167-180 [FREE Full text] [doi:

10.2147/JPR.S40846] [Medline: 23503375]

6. Connelly M, Fulmer RD, Prohaska J, Anson L, Dryer L, Thomas V, et al. Predictors of postoperative pain trajectories in adolescent idiopathic scoliosis. Spine (Phila Pa 1976) 2014 Feb 1;39(3):E174-E181. [doi: 10.1097/BRS.0000000000000099] [Medline: 24173016]

7. Parsons B, Schaefer C, Mann R, Sadosky A, Daniel S, Nalamachu S, et al. Economic and humanistic burden of post-trauma and post-surgical neuropathic pain among adults in the United States. J Pain Res 2013 Jun 17;6:459-469 [FREE Full text] [doi: 10.2147/JPR.S44939] [Medline: 23825931]

8. Madden M, Lenhart A, Duggan M, Cortesi S, Gasser U. Pewinternet. 2013. Teens and technology 2013 URL: http://www. pewinternet.org/files/old-media/Files/Reports/2013/PIP TeensandTechnology2013.pdf [accessed 2017-06-02] [WebCite Cache ID 6qvDRSkXD] 
9. Parker SJ, Jessel S, Richardson JE, Reid MC. Older adults are mobile too!Identifying the barriers and facilitators to older adults' use of mHealth for pain management. BMC Geriatr 2013 May 6;13:43 [FREE Full text] [doi: 10.1186/1471-2318-13-43] [Medline: 23647949]

10. Klasnja P, Pratt W. Healthcare in the pocket: mapping the space of mobile-phone health interventions. J Biomed Inform 2012 Feb;45(1):184-198 [FREE Full text] [doi: 10.1016/j.jbi.2011.08.017] [Medline: 21925288]

11. Stinson JN, Jibb LA, Nguyen C, Nathan PC, Maloney AM, Dupuis LL, et al. Construct validity and reliability of a real-time multidimensional smartphone app to assess pain in children and adolescents with cancer. Pain 2015 Dec;156(12):2607-2615. [doi: 10.1097/j.pain.0000000000000385] [Medline: 26580680]

12. Kirwan M, Vandelanotte C, Fenning A, Duncan MJ. Diabetes self-management smartphone application for adults with type 1 diabetes: randomized controlled trial. J Med Internet Res 2013 Nov 13;15(11):e235 [FREE Full text] [doi: 10.2196/jmir.2588] [Medline: 24225149]

13. Rosser BA, Eccleston C. Smartphone applications for pain management. J Telemed Telecare 2011;17(6):308-312. [doi: 10.1258/jtt.2011.101102] [Medline: 21844177]

14. Reynoldson C, Stones C, Allsop M, Gardner P, Bennett MI, Closs SJ, et al. Assessing the quality and usability of smartphone apps for pain self-management. Pain Med 2014 Jun;15(6):898-909 [FREE Full text] [doi: 10.1111/pme.12327] [Medline: 24422990]

15. Lalloo C, Jibb LA, Rivera J, Agarwal A, Stinson JN. “There's a Pain App for That": review of patient-targeted smartphone applications for pain management. Clin J Pain 2015 Jun;31(6):557-563. [doi: 10.1097/AJP.0000000000000171] [Medline: 25370138]

16. McGillion MH, Watt-Watson J, Stevens B, Lefort SM, Coyte P, Graham A. Randomized controlled trial of a psychoeducation program for the self-management of chronic cardiac pain. J Pain Symptom Manage 2008 Aug;36(2):126-140. [doi: 10.1016/j.jpainsymman.2007.09.015] [Medline: 18395397]

17. Stinson JN, McGrath PJ, Hodnett ED, Feldman BM, Duffy CM, Huber AM, et al. An internet-based self-management program with telephone support for adolescents with arthritis: a pilot randomized controlled trial. J Rheumatol 2010 Sep;37(9):1944-1952. [doi: 10.3899/jrheum.091327] [Medline: 20595280]

18. Palermo TM, Eccleston C, Lewandowski AS, Williams AC, Morley S. Randomized controlled trials of psychological therapies for management of chronic pain in children and adolescents: an updated meta-analytic review. Pain 2010 Mar;148(3):387-397 [FREE Full text] [doi: 10.1016/j.pain.2009.10.004] [Medline: 19910118]

19. Lorig K, Holman H. Arthritis self-management studies: a twelve-year review. Health Educ Q 1993;20(1):17-28. [Medline: 8444622]

20. Ontario. Regulated Health Professions Act, 1991 URL: https://www.ontario.ca/laws/statute/91r18 [accessed 2017-06-02] [WebCite Cache ID 6qvFMqvmw]

21. de la Vega R, Miró J. mHealth: a strategic field without a solid scientific soul. a systematic review of pain-related apps. PLoS One 2014 Jul;9(7):e101312 [FREE Full text] [doi: 10.1371/journal.pone.0101312] [Medline: 24999983]

22. Moher D, Liberati A, Tetzlaff J, Altman DG, PRISMA Group. Preferred reporting items for systematic reviews and meta-analyses: the PRISMA statement. Ann Intern Med 2009 Aug 18;151(4):264-9, W64. [Medline: 19622511]

23. Chou R, Gordon DB, de Leon-Casasola OA, Rosenberg JM, Bickler S, Brennan T, et al. Management of postoperative pain: a clinical practice guideline from the American Pain Society, the American Society of Regional Anesthesia and Pain Medicine, and the American Society of Anesthesiologists' Committee on Regional Anesthesia, Executive Committee, and Administrative Council. J Pain 2016 Feb;17(2):131-157. [doi: 10.1016/j.jpain.2015.12.008] [Medline: 26827847]

24. Katz J, Seltzer Z. Transition from acute to chronic postsurgical pain: risk factors and protective factors. Expert Rev Neurother 2009 May;9(5):723-744. [doi: 10.1586/ern.09.20] [Medline: 19402781]

25. Rabbitts JA, Fisher E, Rosenbloom BN, Palermo TM. Prevalence and predictors of chronic postsurgical pain in children: a systematic review and meta-analysis. J Pain 2017 Jun;18(6):605-614. [doi: 10.1016/j.jpain.2017.03.007] [Medline: 28363861]

26. Theunissen M, Peters ML, Bruce J, Gramke HF, Marcus MA. Preoperative anxiety and catastrophizing: a systematic review and meta-analysis of the association with chronic postsurgical pain. Clin J Pain 2012;28(9):819-841. [doi: 10.1097/AJP.0b013e31824549d6] [Medline: 22760489]

27. Davidson F, Snow S, Hayden JA, Chorney J. Psychological interventions in managing postoperative pain in children: a systematic review. Pain 2016;157(9):1872-1886. [doi: 10.1097/j.pain.0000000000000636] [Medline: 27355184]

28. Donker T, Petrie K, Proudfoot J, Clarke J, Birch MR, Christensen H. Smartphones for smarter delivery of mental health programs: a systematic review. J Med Internet Res 2013 Nov 15;15(11):e247 [FREE Full text] [doi: 10.2196/jmir.2791] [Medline: 24240579]

29. Loo GB, Griffiths KM, Gulliver A. Effectiveness of mobile technologies delivering ecological momentary interventions for stress and anxiety: a systematic review. J Am Med Inform Assoc 2016 Jan;23(1):221-229. [doi: 10.1093/jamia/ocv043] [Medline: 25997643]

30. Direito A, Dale LP, Shields E, Dobson R, Whittaker R, Maddison R. Do physical activity and dietary smartphone applications incorporate evidence-based behaviour change techniques? BMC Public Health 2014 Jun 25;14:646 [FREE Full text] [doi: 10.1186/1471-2458-14-646] [Medline: 24965805] 
31. Jack K, McLean SM, Moffett JK, Gardiner E. Barriers to treatment adherence in physiotherapy outpatient clinics: a systematic review. Man Ther 2010 Jun;15(3):220-228 [FREE Full text] [doi: 10.1016/j.math.2009.12.004] [Medline: 20163979]

32. Wallace LS. A review of pain-related smartphone apps. 2013 Presented at: American Academy of Pain Medicine Annual Meeting; 2013; Fort Lauderdale, FL. [doi: 10.1111/pme.12104]

33. Steele Gray C, Khan AI, Kuluski K, McKillop I, Sharpe S, Bierman AS, et al. Improving patient experience and primary care quality for patients with complex chronic disease using the electronic patient-reported outcomes tool: adopting qualitative methods into a user-centered design approach. JMIR Res Protoc 2016 Feb 18;5(1):e28 [FREE Full text] [doi: 10.2196/resprot.5204] [Medline: 26892952]

34. Devi KR, Sen A, Hemachandran K. A working framework for the user-centered design approach and a survey of the available methods. Int J Sci Res Publ 2012 Apr;2(4):1-8 [FREE Full text]

35. Chan J, Shojania KG, Easty AC, Etchells EE. Does user-centred design affect the efficiency, usability and safety of CPOE order sets? J Am Med Inform Assoc 2011 May 1;18(3):276-281 [FREE Full text] [doi: 10.1136/amiajnl-2010-000026] [Medline: 21486886]

\author{
Abbreviations \\ mHealth: mobile health \\ PRISMA: Preferred Reporting Items for Systematic Reviews and Meta-Analyses \\ UCD: user-centered design
}

\author{
Edited by G Eysenbach; submitted 22.06.17; peer-reviewed by J Prescott, M Mittinty; comments to author 13.07.17; revised version \\ received 14.09.17; accepted 20.09.17; published 23.10 .17 \\ Please cite as: \\ Lalloo C, Shah U, Birnie KA, Davies-Chalmers C, Rivera J, Stinson J, Campbell F \\ Commercially Available Smartphone Apps to Support Postoperative Pain Self-Management: Scoping Review \\ JMIR Mhealth Uhealth 2017;5(10):e162 \\ URL: http://mhealth.jmir.org/2017/10/e162/ \\ doi: $10.2196 /$ mhealth. 8230 \\ PMID: 29061558
}

(C) Chitra Lalloo, Ushma Shah, Kathryn A Birnie, Cleo Davies-Chalmers, Jordan Rivera, Jennifer Stinson, Fiona Campbell. Originally published in JMIR Mhealth and Uhealth (http://mhealth.jmir.org), 23.10.2017. This is an open-access article distributed under the terms of the Creative Commons Attribution License (https://creativecommons.org/licenses/by/4.0/), which permits unrestricted use, distribution, and reproduction in any medium, provided the original work, first published in JMIR mhealth and uhealth, is properly cited. The complete bibliographic information, a link to the original publication on http://mhealth.jmir.org/, as well as this copyright and license information must be included. 